\title{
Anestesiologia na Era da Medicina Baseada em Evidências
}

\begin{abstract}
$\mathrm{A}^{\mathrm{N}}$ Medicina Baseada em Evidências propõe a integração entre as melhores evidências da pesquisa com a experiência clínica do profissional médico e com os valores individuais dos pacientes.

As melhores evidências da pesquisa devem ser entendidas como sendo os resultados relevantes da pesquisa clínica, freqüentemente baseadas em ciências médicas básicas, mas centradas no paciente. As mesmas têm como objetivo fornecer acurácia e precisão aos testes diagnósticos (incluindo o exame físico e exames complementares pré-operatórios), elevar, tanto o poder prognóstico dos indicadores clínicos, como a eficácia e segurança de procedimentos terapêuticos, de reabilitação e preventivos. As novas evidências provenientes da pesquisa clínica podem, em certas situações, invalidar determinadas atitudes médicas previamente aceitáveis e praticadas (diagnósticos/tratamentos), substituindo-as por outras, com maior poder de eficácia e segurança.
\end{abstract}

A experiência clínica deve ser interpretada como a capacidade do médico utilizar os seus conhecimentos e experiências clínicas prévias, no sentido de identificar rapidamente o estado da saúde do paciente, as suas necessidades diagnósticas (pré-operatórias), a sua individual relação risco-benefício frente a potenciais intervenções médicas (drogas e técnicas).

Os valores do paciente devem ser considerados como as preferências, as reclamações e as expectativas individuais que os mesmos apresentam no decorrer da relação clínica médico-paciente, os quais precisam ser integrados como fatores importantes nas decisões das atitudes clínicas a serem exercidas no indivíduo.

Quando esses três elementos são realmente integrados, médicos e pacientes formam uma espécie de aliança diagnóstica e terapêutica que resulta na otimização dos resultados epidemiológicos de morbimortalidade e de qualidade de vida.

Pelo fato de propor que as decisões clínicas sejam um processo explícito, consciente e baseado em sólidos alicerces científicos, esse tipo de prática médica evita as opiniões e atitudes confusas e dúbias, através da evidência. Dessa forma, a Medicina Baseada em Evidências auxilia a sensibilizar o conhecimento crítico do médico, melhorando a qualidade de sua prática clínica, da atividade docente e da pesquisa. No sentido da prática clínica com base na Medicina Baseada em Evidências alguns tópicos devem ser observados:

1. Conversão da informação considerada necessária em relação a testes diagnósticos (exames pré-operatórios...), a procedimento médico (técnicas e drogas) e a relação risco-benefício, em uma questão objetiva;
2. Pesquisa da melhor evidência bibliográfica que responda ao questionamento anterior (MEDLINE, SCIELO etc.);

3. Avaliação crítica da qualidade da evidência através de sua validade, representatividade epidemiológica e o possível impacto de sua aplicação na específica situação apresentada (REVISÃO SISTEMATIZADA DA LITERATURA);

4. Integração entre a aplicabilidade clínica da evidência exposta na literatura, com a experiência prévia do médico e com os valores biológicos e circunstanciais individuais do paciente em estudo;

5. Avaliação da efetividade e eficiência da aplicação dos tópicos descritos e os meios para melhorá-los no futuro.

Aformulação da questão deverá abranger quatro componentes fundamentais: o problema específico do paciente, a intervenção proposta, a aplicabilidade da intervenção proposta pela evidência da literatura no referido paciente e a validade da intervenção em relação a efetividade e morbimortalidade. É importante salientar que diferentes desenhos de estudos científicos na literatura respondem especificamente a diferentes tipos de questões, como por exemplo:

- Questões relacionadas com a terapêutica são melhores respondidas por estudos aleatórios, controlados e duplamente encobertos;

- Questões relacionadas com prognóstico, encontram respostas mais precisas através de estudos tipo caso controle ou estudos de cohort;

- Questões que visam aspectos epidemiológicos e de outcome tem as melhores opções nas meta-análises e nas revisões sistematizadas;

- Os trabalhos científicos acompanhados de editoriais, na maioria das vezes, informam sobre a qualidade científico-assistencial dos mesmos.

A MEDLINE, SCIELO e outras fontes de bancos de dados on line da literatura biomédica tentam apresentar as referências bibliográficas da maneira mais compreensível que lhes é possível, por outro lado, em grande percentual das vezes, o material indexado possui uma mínima aplicabilidade na prática clinica. No sentido de objetivar a pesquisa nas fontes MEDLINE e congêneres, a relação entre o método dos trabaIhos indexados e a sua relevância clínica pode ser descrita com um diagrama em forma de pirâmide, sendo que a maior relevância clínica ocupa o ápice, decrescendo no sentido da base. 


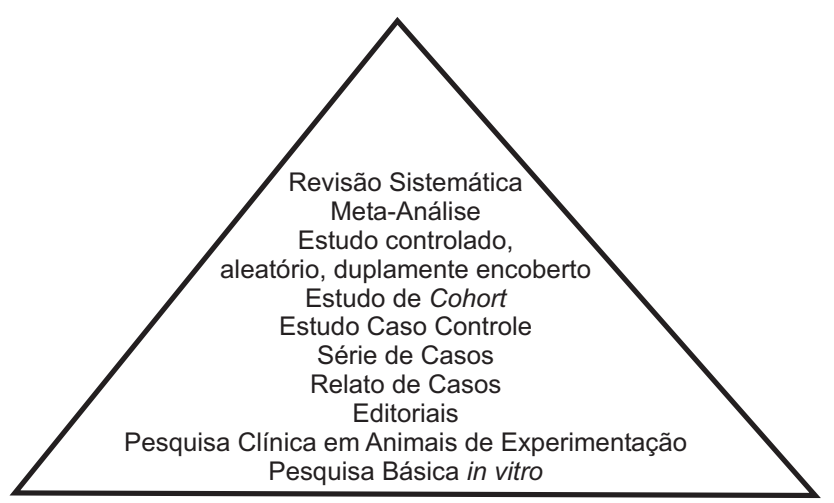

na pirâmide, evidenciam o método científico com potencialidade de demonstrarem conclusões com uma significante representatividade clínica, as quais devem embasar a conduta clínica baseada em evidências. A caracterização minuciosa das opções dos desenhos de estudo com potencialidade de serem utilizados no projeto e execução de trabalhos científicos e a sua correlação com a relevância clínica devem ser discutidas durante a formação do anestesiologista e a sua prática clínica. Dessa forma, criar-se-á uma comunidade anestesiológica com sólidas bases clínico-científicas que entenderá com profundidade as bases metodológicas da pesquisa, podendo julgar a aplicabilidade de seus postulados na sua prática assistencial.

A MEDLINE (National Library of Medicine) é o maior banco de dados, possuindo em torno de 3500 revistas biomédicas indexadas, contendo mais de 11 milhões de referências bibliográficas. Entretanto, essa literatura não esta submetida a nenhum processo de qualificação ou avaliação crítica. Por outro lado, The American College of Physicians Journal Club e a Cochrane Datebase of Systematic Review são exemplos de bancos de dados que oferecem literatura biomédica previamente qualificada e avaliada criticamente.

The American College of Physicians Journal Club seleciona estudos com base no método empregado e elabora resumos associados a uma crítica de forma estruturada realizada por especialistas na área. A Cochrane Datebase of Systematic Review identifica importantes tópicos da pesquisa clínica, orienta a pesquisa das fontes da literatura, localiza e avalia os estudos considerados relevantes, revisa e analisa os resultados apresentados e relata as implicações desses resultados na prática clínica e para as futuras pesquisas.

A partir da pesquisa da literatura realizada com o objetivo de responder a questão clínica elaborada, o médico que pratica a Medicina Baseada em Evidências deverá avaliar criticamente o referido material. Com objetivo de sistematizar a avaliação de estudos publicados na área biomédica o médico pode utilizar a EBM worksheet, que pode ser encontrada no seguinte portal (http://cebm.jr2.ox.ac.uk).
A nova e atual concepção mundial de que a Anestesiologia deverá caracterizar-se como Medicina Perioperatória, participando não somente da realização do ato anestésico, mas envolvendo-se em todo período perioperatório, através da analgesia pós-operatória, tratamento e profilaxia da náusea e vômito, monitorização, ventilação mecânica, tratamento e profilaxia da hipertermia maligna, avaliação clínica pré-operatória, direciona a sua prática no sentido do exercício da Medicina Baseada em Evidências.

Embora a Medicina Baseada em Evidências tenha sido originariamente projetada para aplicação em especialidades clínicas, especialmente a Medicina Interna, Psiquiatria, Medicina Intensiva e Epidemiologia, referente a diagnóstico e terapêutica, especialidades não "terapêuticas", como a Anestesiologia, podem adaptar-se a seus conceitos, diretrizes e postulados, beneficiando-se de seus resultados. Com esse objetivo a Sociedade Brasileira de Anestesiologia, utilizando-se de sua estrutura científica e de formação médica, tem trabalhado no sentido de incluir nos programas de formação em Anestesiologia, atividades que possibilitem a geração e o desenvolvimento de um senso crítico, tanto na avaliação dos projetos do método investigativo dos trabaIhos científicos a serem elaborados (epidemiologia e estatística), como na interpretação sistematizada da literatura já existente. Através desta postura educacional e cultural os futuros anestesiologistas brasileiros aprimorarão a competência na crítica, tanto sobre os projetos para elaboração de trabalhos científicos, como para os novos conceitos de prática clínica preconizados pela literatura atual.

Gastão Fernandes Duval Neto, TSA

Co-Editor da Revista Brasileira de Anestesiologia 